\title{
LA ESCALA DE LOS SERES EN LA FILOSOFÍA DE TOMÁS DE AQUINO
}

\author{
Francisca Tomar Romero \\ Universidad de Barcelona
}

La afirmación de la existencia de una escala de los seres, es decir, que toda la Naturaleza se halla ordenada según un cierto orden o jerarquía, es una doctrina filosófica cuyos orígenes se remontan al Neoplatonismo y que se ha venido repitiendo en toda nuestra tradición filosófica:

Ya en los diálogos platónicos encontramos ocasionales insinuaciones de que las Ideas, y por tanto sus contrapartidas sensibles, no tienen todas igual rango metafísico o excelencia; pero esta concepción, no sólo de las existencias, sino también de las esencias como algo jerárquicamente ordenado, sólo es en Platón una vaga inclinación, no una doctrina específicamente formulada. ${ }^{1}$ Aristóteles, a pesar de su reconocimiento de la multiplicidad de los posibles sistemas de clasificación de la naturaleza, fue quien principalmente sugirió a los naturalistas y filósofos de los tiempos posteriores la idea de clasificar todos los animales, por lo menos, en una única escala natural ordenada según el grado de «perfección». ${ }^{2}$

Pero aunque los ingredientes de dicha doctrina procedan de Platón y de Aristóteles, donde primero aparece totalmente organizada en un esquema general coherente es en el neoplatonismo: La Escala del Ser, tal como implica el principio de la expansividad de la autotrascendencia del «Bien», se convierte en la concepción esencial de la cosmologịa neoplatónica. En ella, las diferencias cualitativas se tratan como necesariamente equivalentes a las diferencias de excelencia, a la diversidad de rangos dentro de una jerarquía. ${ }^{3}$

1 Cf. Lovejoy, A.O., La gran cadena del ser, Barcelona, Icaria Editorial, 1983, p. 73.

2 Cf. Aristóteles, De generatione animalium, 732a 25-733b; Idem, De anima, 414a 29-415a 13.

3 El neoplatonismo tratará de poner de relieve la jerarquía de los términos que componen el orden universal. Las Institutiones theologicae de Proclo, y, en dependencia de esta obra, los escritos del PseudoDionisio Areopagita y el De causis, entre otros, presentan una escala de grados de perfección que se reduce esencialmente a: el ser, la vida, la inteligencia. Cf. Proclo, Institutiones theologicae, c. 101 (pp. LXXXIIILXXXIV); Pseudo-Dionisio Areopagita, De divinis nominibus, V, 3 y 5; Liber de causis. 
Desde el neoplatonismo, esta doctrina de la escala de los seres pasó a los complejos presupuestos que configuraron la teología y la cosmología de la Cristiandad medieval, teniendo su máxima expresión en las tesis de Santo Tomás de Aquino. Pero, en la transmisión de dichas ideas neoplatónicas no debemos olvidar la gran importancia que tuvieron dos autores: San Agustín y el desconocido autor del siglo $\mathrm{V}$ de una extraña colección de escritos erróneamente atribuidos al discípulo ateniense de San Pablo, y que por ello es conocido como Pseudo-Dionisio.

La constancia y vigencia de esta doctrina no es extraña si tenemos en cuenta que la existencia de dicha escala u orden de los seres es un hecho fácilmente comprobable en nuéstra experiencia cotidiana. Nuestra experiencia y sentido común nos muestran que el Mundo, que la realidad es multiforme, es decir, plural y diversa. Los entes se agrupan en géneros y especies, pero aún así los individuos de una misma especie no se confunden entre sí, pues también poseen diferencias individuales. Todas las cosas, todos los entes, son; pero son de diversa manera. Por tanto, la realidad se extiende en profundidad, y junto a una multiplicidad cuantitativa se nos descubre una multiplicidad intensiva: Desde la materia (prope nihil) hasta Dios (omnitudo realitatis) se escalonan todos los seres según su diversa plenitud de realidad o perfección. De esta manera, pues, la realidad no se extiende toda ella en un mismo plano, sino que los entes están escalonados en profundidad, son de modo desigualmente intenso. Es decir, los seres no están situados en un mismo nivel o plano, sino siguiendo un determinado orden o jerarquía según su mayor o menor perfección; perfección que, como trataremos de reflejar a lo largo de este artículo, se corresponde a una mayor o menor plenitud de ser. ${ }^{4} \mathrm{Y}$, por consiguiente, según el orden que ocupen en esta escala o jerarquía, según su mayor o menor perfección o plenitud de ser, les asignamos también un mayor o menor valor.

La teoría de la bondad y de la perfección que San Agustín, inspirándose en el libro de la Sabiduría, propone en su opúsculo De natura boni contra Manicheos y que con tanta reinsistencia y bajo tan variadas formas reaparece en sus obras y en la de otros autores, como San Buenaventura, puede considerarse como uno de los pilares de la filosofía tomista y, más concretamente, de la doctrina sobre la escala de los seres, la cual constituye su más evidente y manifiesta plasmación y que en Santo Tomás encontramos plenamente formulada. ${ }^{5}$

Dicha teoría de raíz agustiniana consiste en la concepción del ser real como constituido por tres elementos solidarios e irreductibles entre sí: la especie, el modo y el orden, ${ }^{6}$ que son las tres dimensiones en que se articula necesariamente todo ser finito y que constituyen la expresión y medida de su perfección. Éstos han sido comunicados por Dios a toda criatura para que reproduzca, en grado original y propio, su infinita Perfección y Bondad. Por este triple

4 Por ello, y puesto que todos los entes participan del ser en mayor o menor medida, a fin de evitar confusiones o equívocos, quizás habría sido más adecuado titular este artículo La escala de los entes en Tomás de Aquino o bien La escala del ser (en el sentido de esse).

5 Véase: Bofill, J., La escala de los seres o el dinamismo de la perfección, Barcelona, Publicacionés Cristiandad, 1950.

6 Cf. Santo Tomás, Summa Theologiae, I, q. 5, a. 5. 
carácter las criaturas penden de Él y lo revelan como su primera Causa ejemplar, eficiente y final. $^{7}$

La species de un sujeto nos da la medida de su dignidad. Y como todo lo que hay en el Universo de digno, de noble, de generoso, la filosofía tomista lo comprende en la denominación de acto, entonces la perfección de una species será, exactamente, su actualidad. La species es el aspecto propiamente conceptualizable del ente. Y precisamente por su primacía en este orden de relaciones a que pertenecen las de conocimiento, tiende de sí a absorber totalmente la atención intelectual.

Junto a esta perfección esencial, la species, aparece, completándola y limitándola a la vez, una perfección existencial rigurosamente complementaria de aquella: el modus. ${ }^{8}$ Este modus, que constituye el segundo elemento de la perfección finita ( 0 , lo que es lo mismo, el segundo elemento del ente perfecto), es la vertiente existencial en que la esencia queda concretada, 0 modalizada, pues supone la posesión finita de la actualidad del esse. Por el modo el ser se recibe y se concretiza en una especie y la especie en un individuo. Así pues, el modo es el elemento existencial, el que determina los atributos situales, la existencia, la temporalidad, y hace del ente un sujeto.

Pero junto a la species, término de relaciones de ejemplaridad, y al modus, término de eficiencia, hay un tercer elemento que constituye al supuesto en término de relaciones de finalidad. Es la capacidad que acompaña y distingue a la perfección de poder comunicarse a otros, y de tender a esta comunicación. Se trata del ordo o tercer elemento de la perfección finita, cuya naturależa no es estática, sino ponderal. Este orden no es simplemente posicional, sino funcional; es el elemento en virtud del cual el ente realiza un valor. Por tanto, el orden es la dimensión ontológica que significa el dinamismo tendencial de las cosas. Por el orden adquiere un supuesto su última perfección, fundada y exigida por la especie y el modo.

La proyección de esta noción de orden en el marco más amplio del Universo desempeña un importante papel en el pensamiento de Santo Tomás, ya que éste tiene una amplia visión de la Naturaleza como un orden de los seres según su mayor o menor perfección, poder y bondad: ${ }^{9}$

Un orden quiere decir, no una simple multiplicidad, sino una multiplicidad unificada. Esta unificación podría ser simplemente extrínseca; pero vemos que el orden de los seres es más que esto, es más que una simple disposición o posición suya de hecho, en tal o tal otro lugar. Nos percatamos de que el orden que reina entre ellos es un orden debido, es la expresión de una exigencia interna que supone un deber ser, es decir, un principio y un fin.

7 Por tanto, si referimos esta estructura triádica del ente como species, modus y ordo a la doctrina de las causas, resulta que la species será la dimensión del ente en virtud de la cual es término de relaciones formales de ejemplaridad; el modus, la que lo constituye en término de relaciones de eficiencia, que lo ponen como existente; y el ordo será aquella dimensión del ente que lo constituye en término de relaciones tensionales de finalidad.

8 El tomismo no prescinde de ninguno de los dos aspectos (species y modus), sino que los armoniza en una visión más alta, por lo que no puede clasificarse adecuadamente ni como un sistema esencialista ni como un existencialismo, sino que trata de integrar ambos aspectos de la realidad.

9 Cf. Santo Tomás, Summa contra Gentiles, III, c. 20; Ibid., II, c. 68. 
En segundo lugar, todo orden requiere una distinción: Implica que los seres se acomoden en diverso grado a un prototipo ideal que constituye su medida. La multiplicidad indiferenciada, lo meramente cuantitativo no puede ser sujeto de un orden; sino que el orden exige, constitutivamente, una jerarquía, es decir, el establecimiento de grados o clases.

Y esto se refleja claramente en el orden total del Universo: La inteligencia descubre en el Mundo no una multiplicidad caótica de cosas ni de fenómenos, sino un cosmos, un grandioso conjunto de seres escalonados según su perfección, trabados unos con otros con innumerables relaciones que, tomadas en su conjunto, le ofrecen desde el primer instante un sentido, pues se le presentan como un índice gigantesco que apunta hacia su Creador.

Por tanto, distinción y unidad son los elementos constitutivos de todo orden que, aplicados a la Naturaleza, hacen que ésta sea concebida como una diversidad unificada.

La unidad es anterior a la diversidad y constituye su origen. Pero la diversidad no brota de la unidad como diversidad pura, sino siempre constituyendo un ordo, una compositio o sintesis. Por tanto, junto a la importancia de la unidad, toda concepción del orden debe remarcar la necesaria distinción y jerarquía que se da entre los seres, ya que donde hay orden, ha de haber distinción. ${ }^{10}$ Pero esta razón de ser expresada por el orden puede ser múltiple, por lo que la palabra orden es susceptible de diversos matices:

En primer lugar, puede expresar una relación dinámica, una relación de finalidad: Todo ser, en efecto, tiende a un fin, está ordenado a su fin. Pero también puede expresar una relación de causa formal. Sin embargo, este segundo aspecto del orden como perfección formal de toda multitud puede todavía subdividirse en dos: el orden situal, es decir, aquella disposición de las partes por la que cada una de ellas ocupa el lugar que le corresponde; y el orden como equivalente de clase, o de grupo, -de conjunto de elementos que tienen características semejantes.

Entre estos tres sentidos de la palabra orden, el primero, el orden de finalidad, es el más elevado, y la razón de ser de los demás, por lo que podríamos afirmar que el orden es el resultado de la finalidad. Así pues, cuando se define la filosofía de Santo Tomás como una filosofia del orden, ${ }^{11}$ el término orden no se refiere sólo al orden estático o situal, sino que debe ser entendido como el resultado de la finalidad y, por consiguiente, como un orden dinámico o tendencial. De esta manera, siguiendo al Aquinate, podemos establecer una noción de orden en la que no sólo se tiene en cuenta la distinción formal o específica entre los distintos seres, sino también la unidad en la consecución del fin. Por lo tanto, si bien cada uno de los seres ocupa su propio lugar, mantiene con los otros relaciones de semejanza, eficiencia y finalidad. Existe, pues, una ordenación de los seres en virtud de su mayor o menor perfección que viene en gran medida definida no sólo por los esquemas de un finalismo inmanente; sino también, y muy especialmente, por un finalismo trascendente.

En relación con esta noción de orden, afirma Santo Tomás que: «Entre toda realidad creada, la mejor es el orden del Universo, en el que su Bien consiste». ${ }^{12}$ Sin embargo,

10 Idem, Summa Theologiae, I-II, q. 105, a. 4.

11 Véase: García López, J., Tomás de Aquino, maestro del orden, Madrid, Cincel, 1984.

12 Santo Tomás, Summa contra Gentiles, II, c. 42. 
puntualiza que «el bien del orden del Universo no es el último Fin del Universo, sino que se ordena a un Bien exterior como a su último Fin». ${ }^{13}$ Según esto, el orden de la Naturaleza, con cada uno de los seres que la componen, se explica por la participación común de todos ellos en un movimiento ascensional, de convergencia hacia Dios, buscando la unión con Él, como con su Bien.

Tras esta breve aproximación a la noción de orden, debemos examinar a continuación ese otro concepto al que está íntimamente vinculado, y en cuya mutua referencia alcanzan ambos su plena significación: Nos referimos al concepto de perfección.

Podemos distinguir dos sentidos primordiales del término perfecto: lo perfecto como acabado («perfectum ut consummatum») y lo perfecto como noble («perfectum ut nobile»): Según la primera acepción, lo perfecto es lo opuesto a lo germinal e incipiente, es lo que tiene la plenitud de ser debida a su naturaleza. Expresa, entonces, la condición de un sujeto que es acabado, actual, completo en su orden. En este sentido se distingue entre perfección substancial, perfección integral y perfección final o situal, según los diversos momentos o grados de actualidad de un sujeto en su perfección. Así, la perfección substancial es la que posee un supuesto con sólo traspasar los umbrales de la existencia, por el becho de pertenecer a una especie. Y como en lo substancial no hay más o menos, resulta que esta primera perfección se da por igual en todos los sujetos de un mismo orden y permanece invariable a lo largo de toda su vida. Laperfección integral corresponde a un segundo momento en el que el sujeto, después de un período de desarrollo y crecimiento, se nos presenta en el pleno disfrute y posesión de sus facultades; es decir, su perfección substancial se ha visto completada por las propiedades accidentales que pide en cada caso la naturaleza del sujeto. La última perfección de un ser, la perfección final o situal se da por su adhesión y contacto con el fin extrínseco para el cual ha sido hecho. ${ }^{14}$

En un segundo sentido, lo perfecto se opone no a lo germinal e incipiente, sino a lo bajo y vil. De esta manera, con la calificación de lo perfecto como noble se define a lo perfecto como lo valioso, poderoso o eminente. ${ }^{15}$ Los diferentes grados de perfección (entendida como nobleza) que se dan en los seres consistirían en su diverso modo de participar en el ser. ${ }^{16}$

Por otra parte, existe una absoluta prioridad o primacía de lo perfecto en todos los órdenes de la Naturaleza, ya que incluso está en el fondo de lo imperfecto, fundamentándolo a modo de razón de su ser y de su valor. Esta conclusión es extraída del hecho de que si bien se puede observar un doble aspecto del orden de la Naturaleza: por una parte, el orden de la generación y el tiempo (según el cual es antes lo imperfecto y en potencia) y, por otra, el orden de la perfección o intención de la Naturaleza (por el que lo perfecto es anterior a lo imperfecto); sin embargo, podemos constatar que lo perfecto es antes que lo imperfecto no sólo por naturaleza, sino incluso en el orden del tiempo, ya que sólo lo perfecto puede llevar a otros a la perfección. ${ }^{17}$

13 Idem, Summa Theologiae, I, q. 103, a. 2, ad. 3; Cf. Idem, De Potentia, q. 7, a. 9.

14 Cf. Idem, Summa Theologiae, I, q. 6, a. 3.

15 Cf. Idem, Summa Theologiae, I, q. 2, a. 3; I, q. 4, a. 1; Idem, Summa contra Gentiles, I, c, 28 y 70.

16 «Secundum modum quo res habet esse est suus modus in nobilitate» (Santo Tomás, Summa contra Gentiles, I, c. 28).

17 Cf. Santo Tomás, Summa Theologiae, I, q. 85, a. 3, ad 1; Idem, In Metaph., IX, lect. 7, n. 1844 y ss.; Ibid., XII, lect. 6, n. 2506ss. 
Las tesis ya expuestas acerca del orden del Universo y del concepto de perfección, implican la existencia de una Escala de los seres en la que ambas confluyen necesariamente y que constituye su más fiel y manifiesta expresión. Según esta doctrina neoplatónica, que es incorporada y plenamente desarrollada por Santo Tomás en su sistema, los seres de la Naturaleza están gradualmente ordenados en diferentes especies en razón de su mayor o menor perfección, y siguiendo el principio de que el ser más alto en un orden alcanza al menos perfecto del orden inmediatamente superior. Pero si hasta ahora nos hemos limitado a señalar la existencia de dicha escala de los entes, es decir, a constatar que en el Universo los seres se hallan ordenados siguiendo una determinada jerarquía, a continuación vamos a intentar analizar y clarificar los principios y relaciones que sustentan y fundamentan esta ordenación de la Naturaleza según Santo Tomás.

En este sentido, no podemos menos que recoger y citar un rico y denso texto del Aquinate cuyo contenido es fundamental para poder entender su concepción de la escala del ser:

\begin{abstract}
«De la misma manera ocurre, pues, en las partes del Universo. Cada criatura, primeramente, es para su propio acto u operación. En segundo lugar, las criaturas menos nobles son para las más nobles, como las inferiores al hombre para el hombre. Cada una de ellas, en tercer lugar, es para la perfección del Universo. Finalmente el Universo todo, con cada una de sus partes, está ordenado a Dios como a su Fin, en tanto que representan por cierta imitación la Bondad divina, para gloria de Dios; aunque las criaturas racionales tienen por fin a Dios de un modo especial, ya que son capaces de alcanzarlo por su operación conociéndole y amándole». ${ }^{18}$
\end{abstract}

Se impone, por tanto, lanecesidad de examinar brevemente la significación e implicaciones de este rico texto, explicitando su contenido. $Y$ esto es lo que trataremos de hacer a lo largo de este artículo:

En primer lugar, observamos que Santo Tomás se refiere a la operación como fin y perfección de todo supuesto: ${ }^{19} \mathrm{La}$ define como el fin de la substancia creada y como la última actualidad de un supuesto. ${ }^{20}$ Así pues, la operación propia de un ser es aquella que le caracteriza, confiere valor y define entre sus semejantes. Pero, además, tiene valor de fin (pues es creadora de unidad), ya que por ella el ser cumple su destino perfeccionándose según su propia naturaleza.

Un ente no puede ser definido por su sola esencia, ${ }^{21}$ sino que la inteligibilidad del ente es su actualidad, y ésta se obtiene por la operación, en la cual y por la cual el esse se realiza como tal. Por consiguiente, la actualización o actuación del ente postula la mediación de la

18 Idem, Summa Theologiae, I, q. 65, a. 2.

19 «Omnis enim res propter suam operationem esse videtur: operatio enim est ultima perfectio rei». (Santo Tomás, Summa contra Gentiles, III, c. 113).

20 Santo Tomás, Summa Theologiae, I, q. 105, a. 5, in c. Cf. Idem, Q.D. De Vir., a. 1; Summa contra Gentiles, III, c. 69, 113; II De Caelo.

21 Cf. Idem, Summa Theologiae, I, q. 84, a. 7. 
operación, del obrar. La operación es, así, el modo interior de individuación universal, es decir, el modo que tiene el ente de salir de su indeterminación abstracta para constituirse en plena identidad con él mismo: En la operación un ente es lo que es, obtiene su plena consistencia ontológica.

Sin embargo, contra la doctrina de la perfección por la operación surge el grave reparo de su fugacidad y transitoriedad. Ante esta objeción, podemos afirmar, siguiendo a Santo Tomás, que existen dos clases de acción: «una que procede hacia una materia exterior, como quemar o cortar; otra que permanece en el sujeto mismo, como sentir, querer o entender». Pero, sólo la segunda es propiamente acto y perfección del agente. ${ }^{22}$

Ser una verdadera sustancia es tener operación propia, ya que la operación es la actualidad y perfección del suppositum, ${ }^{23}$ su télos o cumplimiento. En definitiva, el aforismo clásico operari sequitur esse, que indica la conexión necesaria entre estos dos polos de la inevitable distensión del acto en todo ente finito, podría interpretarse como ser es obrar. En este sentido la noción de vida establece un puente entre las de esse y operación. Así, referida a la operación, la vida excluye la superficialidad y la inautenticidad en el obrar: La operación, como acto vital, está enraizada en el ser del sujeto; es la manifestación espontánea, per modum naturae de este ser. La vida (espontaneidad, sinceridad, autenticidad en el obrar) es actividad por modo natural y excluye lo epifenoménico, la dispersión en la acción. ${ }^{24}$

Dentro de esta escala de los seres debemos entender la vida ontológicamente, es decir, como un grado en la escala de la participación de lòs entes en la actualidad y perfección del ser: $\mathrm{Si}$ consideramos las cosas en cuanto que son, el vivir no podrá ser interpretado como una cualificación perfectiva del ser de ciertos entes; añadido a su ser o actualidad en cuanto entes; sino que el vivir es en sí mismo un nivel de perfección en el ente, por lo que no se puede dar razón de él sino por el modo en que el ente viviente participa, más perfectamente que el no viviente, del ser. ${ }^{25}$

Esta ontología de la vida, que se patentiza en los grados de perfección de la escala de los seres, es expuesta por Santo Tomás en dos textos fundamentales: ${ }^{26}$

En el que se encuentra en la Suma Teológica ${ }^{27}$ se gradúa a los vivientes según su actividad por la línea apetitiva. Así, después de caracterizar a la vida por el movimiento espontáneo, ya que son vivientes los entes que según su naturaleza les conviene moverse a sí mismos para obrar, indica Santo Tomás que la vida será más perfecta en aquellos vivientes que sean menos movidos por otro, es decir, que se muevan de un modo más independiente o autónomo, ya que «si la vida se atribuye a los entes que obran por sí mismos y no movidos por otros, cuanto con mayor perfección convenga esto a un ente, tanto más perfecta será la vida que hay en él». ${ }^{28}$

22 Ibid., I-II, q. 3, a. 2, ad 3; Cf. Idem, De Veritate, q. 8, a. 6, in c.

23 Cf. Idem, Summa contra Gentiles, III, c. 113.

24 Cf. Bofill, J., «Para una metafísica del sentimiento», en Idem, Obra filosófica, Barcelona, Ariel, 1967, pp. $130-131$.

25 Cf. Canals, F., Sobre la esencia del conocimiento, Barcelona, P.P.U., 1987, pp. 589-608.

26 Cf. Forment, E., Introducción a la metafísica, Barcelona, Publicaciones y Ediciones de la Universidad de Barcelona, 1984, pp. 163 ss.

27 Santo Tomás, Summa Theologiae, I, q. 18, a. 3.

28 Ibid. 
Atendiendo a esta autonomía aparecen varios grados de vida (con una analogía de proporcionalidad propia) en los que hay que tener presente el fin de las operaciones de los vivientes, la forma por la que obran, y la ejecución de la acción..$^{29}$ Así, el primer grado de vida lo ocupan los vegetales que no son más que ejecutores. En el segundo grado de vida se encuentran los animales que poseen ya más autonomía en su acción. Pero un mayor enriquecimiento en la actividad autónoma se da en el tercer grado de vida, al que pertenece el hombre, el cual mediante su inteligencia mide y coordina los medios y los fines, así como su forma de obrar. No obstante, la vida intelectiva del hombre no es plenamente autónoma, ya que le son dados por naturaleza los primeros principios y la inclinación al fin último. Por tanto, la vida suprema, plenamente autónoma, corresponde a Dios.

El segundo texto en cuestión corresponde a la Suma Contra los Gentiles..$^{30}$ En él Santo Tomás expone la ontología de la vida, y coloca a los distintos entes en un orden basado en la perfección de sus operaciones, y la perfección de éstas la mide por el grado de intimidad del efecto producido. De este modo, nos describe el espectáculo del orden del Universo, y nos hace ascender, peldaño a peldaño, la escala de los seres, detallándonos las diversas modalidades que reviste sucesivamente la Acción en un supuesto a medida que nos elevamos en la Escala del Ser. Por tanto, como los seres se conocen por sus obras, es atendiendo a ellas como descubre el Angélico en cada caso el valor y perfección de los seres; y así justifica filosóficamente, una clasificación que la razón ya había espontáneamente descubierto.

Dicho texto, por su claridad y concisión no requiere una mayor explicitación, no obstante podríamos resumirlo diciendo que en él Santo Tomás, en base al principio ya expuesto de que la perfección de una operación se mide por la intimidad del efecto producido, establece una clasificación dentro de la escala de los seres cuyo orden ascendente sería el siguiente: seres inanimados (caracterizados por una extroversión absoluta), vida vegetativa (en la que aparece un primer indicio de interioridad, aunque imperfecto todavía), vida sensitiva (cuya operación característica, el conocimiento sensible, constituye un notable progreso en la intimidad pues es ya un proceso de interiorización que implica cierto grado de conciencia y de juicio) y por último la vida intelectiva o vida según el intelecto.

De esta manera, la vida es contemplada como perfección de la naturaleza del ente, y la intelectualidad como el grado supremo de vida. No obstante, desde esta escala de los seres se comprende que el ser sea más perfecto que la vida, y ésta más perfecta que la sabiduría, porque el ser es concebido como acto, como perfección suprema; el vivir como grados de ser o niveles de perfección, y el entender como un grado pleno y supremo de participación en el ser y en el vivir.

Con la vida intelectual (secundum intellectum) llegamos a la forma más alta o superior de vida, que se manifiesta en el poder de reflexión y hace que el viviente sea dueño de su propio

29 «En los entes que se mueven y son movidos se encuentran tres elementos por este orden. Ante todo, el fin, que es el que mueve al agente; el agente principal, que es el que obra por su forma, si bien en ocasiones lo hace por medio de algún instrumento que, sin embargo, no obra en virtud de su forma propia, sino a impulso del agente principal, de suerte que al instrumento sólo corresponde la ejecución del acto». (Santo Tomás, Summa Theologiae, I, q. 18, a. 3).

30 Santo Tomás, Summa contra Gentiles, IV, c. 11. 
juicio y, por consiguiente, también de sus designios. Su actividad y, por tanto, su perfección y felicidad son ahora interiores: su vida, en definitiva, se desarrolla en su interior o intimidad. No obstante, dentro de la vida intelectual se pueden distinguir tres grados: la persona humana (cuya vida superior no alcanza aún la perfecta inmanencia), el ángel (desligado de todo cuerpo y cuyo conocimiento no procede ya del exterior, pues no necesita instrumento material alguno para alcanzar su último fin) y Dios (Operación subsistente en la que objeto y sujeto son formalmente una misma Esencia y Realidad, y que constituye, por tanto, la Vida perfecta, la perfecta inmanencia y objetividad).

Así pues, dentro de esta visión jerárquica de la Naturaleza como un orden de los seres según su mayor o menor perfección, poder y bondad, el hombre ocupa una posición intermedia o medianera, ya que si por su vida activa se le puede colocar en la cúspide de los animales superiores, su vida contemplativa le lleva a ocupar el último lugar entre los seres espirituales, ${ }^{31}$ por lo que hace de frontera divisoria, de horizonte, entre el orden de los seres corruptibles y el de los incorruptibles.

Retomando nuestro comentario o explicitación del texto del Aquinate, comprobamos que, en segundo lugar, afirma que «las criaturas menos nobles son para las más nobles, como las inferiores al hombre para el hombre». ${ }^{32}$ Por tanto, Santo Tomás establece una noción de orden en la que no sólo considera la distinción formal o específica entre los distintos seres, sino también la unidad en la consecución del fin. De esta manera, si bien cada uno de los seres ocupa su propio lugar, mantiene con los otros relaciones de ejemplaridad, eficiencia y finalidad: Las partes del Universo dicen orden entre sí en tanto que una obra sobre otra, o es su fin o ejemplar.

Existe, pues, una ordenación de los seres en virtud de su mayor o menor perfección que viene en gran medida definida por las relaciones de finalidad. La relación es considerada necesaria para la perfección ${ }^{33}$ (si bien no toda relación es, sin más, ennoblecedora), y la perfección es vista como consecución del fin: «Un ser se dice que es perfecto cuando alcanza su fin propio, que es la última perfección de la cosa». ${ }^{34}$ En suma, podemos decir que en la Naturaleza existe una unión y continuidad jerárquica entre los seres de manera que los seres inferiores (o más imperfectos) se ordenan a los superiores.

En tercer lugar, Santo Tomás se propone reflejar cómo las criaturas se ordenan en aras a la perfección del Universo: Todo ente finito encuentra su perfección última fuera de sí mismo. Por tanto, los seres (cosas o Personas) no pueden encontrar su perfección completa en la formación de sistemas cerrados, inconexos unos con otros, sino que la perfección y bondad de los seres exigen su unidad; ${ }^{35}$ su perfección completa, por consiguiente, una unidad de totalidad.

31 «El hombre, animal racional, está constituido de tal suerte que lo más alto de la naturaleza corporal alcanza en él lo más ínfimo de la naturaleza espiritual». (Santo Tomás, Summa Theologiae, I, q. 47, a. 2; Ibid., I, q. 61, a. 3.

32 Santo Tomás, Summa Theologiae, I, q. 65, a. 2.

33 Cf. Idem, De Potentia, q. 7, a. 9.

34 Idem, Summa Theologiae, I, q. 184, a. 1, in c.

35 «Unitas pertinet ad rationem bonitatis». (Ibid., I, q. 103, a. 3). 
Esta unidad, por pertenencia a la cual son los seres perfectos, es el Mundo, totalitas rerum, el cual, precisamente por ser totalidad, no puede ser sino uno. ${ }^{36}$ Así, afirma que el mundo posee una unidad que define como unidad de orden. ${ }^{37} \mathrm{Y}$ este orden universal resultante es lo que de más perfecto hay en la Naturaleza entera: «Entre toda realidad creada, la mejor es el orden del Universo, en el que su Bien consiste». ${ }^{38}$ Pero este bien del orden del Universo no es su último Fin, sino que se ordena a un Bien exterior como a su último Fin. ${ }^{39}$

A continuación, y en cuarto lugar, el Aquinate pasa a ocuparse del hecho de que el Universo entero, junto con cada una de sus partes, está ordenado a Dios como a su Fin. De esta manera, antepone a la finalidad interna o inmanente del Universo una finalidad externa transcendente a él: Los seres que integran la Naturaleza comparten un común y natural deseo de participación o unión con Dios (Sumo Bien), al que aspiran ordenadamente.

En resumen, podemos decir que los seres no sólo se ordenan entre sí en vistas a la realización de sus operaciones propias y a la consecución de un orden universal o del conjunto, siguiendo el esquema de un finalismo inmanente; sino que todos los entes naturales, en su tendencia al bien, quieren participar en la perfección divina, y esto es lo que se conoce como finalismo trascendente: Todas las cosas tienden a participar de Dios no sólo en cuanto Ser, sino también en cuanto Bondad. Todos los seres se ordenan a la Bondad divina como a su Fin. ${ }^{40}$

Siguiendo a Santo Tomás, hemos analizado cómo el orden de la Naturaleza, con cada uno de los seres que la componen, se explica por la participación común de todos ellos en un movimiento ascensional, de convergencia hacia Dios, buscando la unión, la semejanza con Él, como con su Bien. ${ }^{41}$ Llegados a este punto cabe preguntarse qué relación de semejanza guardan las criaturas respecto a Dios. A esta cuestión, y de acuerdo con el Aquinate, debemos responder que, a pesar de que Dios es perfectísimo y su distancia respecto a las criaturas es infinita, existe, sin embargo, en éstas una semejanza de Dios, ya que en el efecto hay siempre una semejanza de la forma del agente. ${ }^{42}$ Esta forma a cuya semejanza han sido producidas las criaturas (y que cada una de ellas, al no poseerla de modo perfecto por su esencia, intenta alcanzarla en lo posible a través de su operación) es la misma Bondad de Dios. ${ }^{43}$

Nuestro autor señala que se habla de semejanza en un sentido no unívoco, sino análogo, pues «todo efecto representa de alguna manera a su causa, pero de diverso modo». ${ }^{44}$ Así distingue dos géneros de semejanza representativa: la representación de vestigio (propia de aquellos efectos que representan tan sólo la causalidad de la causa, no su forma) y la

36 Cf. Ibid., I, q. 47, a. 3.

37 «El Mundo se llama uno por su unidad de orden» (Santo Tomás, Summa Theologiae, I, q. 47, a. 3, c.; Cf. Idem, In VII Metaph. lect. 17, n. 1673).

38 Idem, Summa contra Gentiles, II, c. 42.

39 Idem, Summa Theologiae, I, q. 103, a. 2, ad 3.

40 Cf. Ibid., I, q. 65, a. 2, ad 2.

41 Cf. Idem, Summa contra Gentiles, III, c. 24.

42 Idem, Summa Theologiae, I, q. 4, a. 3.

43 Idem, Compendium Theologiae, c. 101.

44 Idem, Summa Theologiae, I, q. 45, a. 7. 
representación de imagen (que se da en los efectos que representan la causa por semejanza con su forma; es decir, no simplemente dan a conocer su causa, sino que imitan su forma en lo que tiene de específico). ${ }^{45}$ Debido a su naturaleza intelectual, las criaturas racionales son las únicas que, propiamente hablando, son a imagen de Dios (y ello tanto más perfectamente cuanto más perfecta sea su naturaleza intelectual). ${ }^{46}$

Pero no sólo hay una diferencia de grado en la participación de la perfección divina, sino que hay una diferencia más esencial que consiste en que unos seres alcanzan inmediatamente el Fin y otros no, pero estos últimos ayudan o ponen las condiciones necesarias para que los otros lo alcancen. Por tanto, no todos los seres alcanzan su Fin último de la misma manera:

«Todos los seres se ordenan a la Bondad divina como a su Fin, pero los hay que son más cercanos a este Fin y que participan, por ello, más plenamente de la divina Bondad; de lo cual se sigue que los que son inferiores... se ordenan de alguna manera a ellos. En todo orden de fines, en efecto, los más cercanos al Fin son fin a su vez con respecto a los más alejados de él, de la misma manera que en un orden de causas eficientes la virtualidad del agente primero alcanza sus últimos efectos mediante las causas intermedias.

Así ocurre en el orden del Universo: los inferiores consiguen sobre todo su fin en cuanto se ordenan a sus superiores, y siendo así que la naturaleza espiritual es superior a la corporal, se sigue que toda la naturaleza corporal se ordena a la espiritual». ${ }^{47}$

De todo lo anterior se deduce que esta unión con Dios, que es el último Fin de toda criatura, y por consiguiente su perfección, puede tener lugar de dos maneras: ${ }^{48}$

- Por vía natural o intencionalidad física: Esta perfección es general, común a todas las criaturas y consiste en la participación por semejanza de la Perfección y Bondad divinas.

- Por vía intencional o intencionalidad psíquica: Es la perfección propia de la Persona en tanto que Dios es el objeto de su conocimiento y amor.

La unión con Dios por vía intencional es el modo más perfecto, y el único en sentido propio y pleno, de alcanzar el Fin último o unión con Dios. Este modo particular y perfectísimo de realizar el Fin común a toda criatura es propio y exclusivo de la Persona (o criatura intelectual); en cuanto sólo ella puede tener a Dios como objeto de su conocimiento y de su amor.

El resto de los seres no alcanzan el fin del Universo más que de un modo secundario o impropio, mediante la participación analógica de la semejanza divina (vía natural); es decir, participando de in modo finito y limitado de una perfección de Dios que es una imitación de la perfección divina: Buscan la semejanza con Dios para participar, en la medida de lo posible, en la Bondad divina. ${ }^{49}$

45 Ibid.

46 Cf. Ibid., I, q. 93, a. 3-4. Cabe destacarse que en la Persona la semejanza con Dios cambia de orden, por lo que, con respecto a los seres inferiores, existe una diferencia no simplemente de grado en la semejanza o participación de la bondad divina por parte del hombre.

47 Santo Tomás, Op. II, Compendium Theol., c. 148; Cf. Idem, Summa Theologiae, I, q. 65, a. 2, ad. 2.

48 Cf. Bofill, J., La escala de los seres, op. cit., pp. 63-66.

49 «Todos los seres desean, pues, la semejanza con Dios como su último Fin». (Santo Tomás, Summa contra Gentiles, III, c. 24). 
La perfección natural es poseída por todas las criaturas, ya que es inseparable del esse: $\mathrm{La}$ intencionalidad en un sentido amplio (o intencionalidad física) se manifiesta en todos los entes, en la medida en que el Ser es poseído por cada ente, y no hay realidad alguna que no cuente, en la medida de su perfección o nobleza, con este haber ontológico. Esto es así debido a que el ser es, en las cosas, el efecto de la presencia de Dios; pues Dios está en todas y cada una de las criaturas por esencia, presencia y potencia.

No obstante, la perfección de todo supuesto, considerado en sí mismo, es imperfecta. Es decir, en una cosa cualquiera, considerada en sí misma, su perfección es imperfecta, como parte que es de la perfección de todo el Universo. El modo de ser de la parte en cuanto tal es, precisamente, tener .en sí misma una perfección imperfecta (ya que la parte no tiene por sí misma razón de ser, no puede ser considerada en sí misma de modo definitivo, sino que posee su último sentido en el todo al que está vinculada). De este modo, la determinación específica de los seres, que es condición de su posibilidad, es a la vez una determinación perfectiva y una determinación limitativa.

Esta limitación en su perfección nos hace percatarnos de la condición de parcialidad de los seres particulares, que nos obliga a sacrificar de algún modo su individualidad integrándolos en un Todo que da razón de su inteligibilidad. Pero en el caso del hombre, donde la individualidad se identifica con la personalidad, la aplicación de este mismo esquema de explicación nos llevaría a la destrucción de la Persona. Siguiendo a Santo Tomás, podemos resolver dicha cuestión afirmando que junto a esta perfección natural (o perfección del ser según la especie), se da un segundo modo de perfección en los seres creados: la perfección del ser cognoscente en cuanto tal, , $^{50}$ por la cual la perfección misma de un ser se encuentra, al propio tiempo, en otro. Esta perfección por el conocimiento es propia de los seres superiores y, transcendiendo todo límite, hace posible que en un solo sujeto se concentre la perfección de todo el Universo, ya que, en cierta manera, permite recibir en sí la perfección de todo otro ser. La actividad intelectual presupone un salir de sí mismo, lo que aporta una cierta perfección a la limitación propia del ye.

Por tanto, el conocimiento por parte de los seres superiores es èl remedio o solución a esta finitud, tanto específica como individual, propia de todo supuesto natural. Y esta perfección por el conocimiento ha sido tradicionalmente considerada por los filósofos como la más alta perfección a que el alma podía aspirar, ya que permitía encerrar en sí la representación de todo el orden del Universo y sus causas.

No obstante, en su análisis acerca de las condiciones en que se da el conocimiento pone la inmaterialidad como la única condición para que el conocimiento sea posible. Por tanto, la inmaterialidad es condición del conocimiento y medida de su perfección tanto por parte del objeto como del sujeto. En definitiva, ello es lo que representa el fundamento metafísico de la teoría tomista del conocimiento con su reducción del orden del conocimiento al orden del ser. Por consiguiente, tanto la capacidad de conocer, como la capacidad de ser conocido, dependen y están causadas por un cierto grado de inmaterialidad. ${ }^{51} \mathrm{Y}$ el grado de inmaterialidad perfecta

50 Cf. Santo Tomás, Quaestiones Disputatae. De Veritate, II, a. 2.

51 Cf. Idem, Quaestiones Disputatae. De Veritate, II, a. 2; Idem, Summa Theologiae, I, q. 14, a. 1; Idem, De Spiritualibus Creat., a. 1, ad 12; Idem, Summa contra Gentiles, I, c. 44. 
corresponde a Dios, en el que se da una total ausencia de pasividad, de accidentalidad o determinación; por lo que Dios es una inteligencia pura, una forma pura que constituye el supremo ejemplar por cuya participación todos los otros seres son inteligibles.

Sin embargo, la presencia posible de una cosa en nosotros como contenido psíquico no está reducida al orden del conocimiento, sino que existe un doble modo de presencia intencional, objetiva, de los seres de la Naturaleza: Los seres no tan sólo están en nosotros en la línea de la representación y de la forma, sino además, en la línea de la actividad y del amor. Y esta idea es la expresada en su afirmación de que: «las criaturas racionales tienen a Dios por fin de un modo especial, ya que son capaces de alcanzarle por su operación, conociéndole y amándole».52

Por consiguiente, conocimiento y amor, además de ser las dos formas psíquicas correlativas de la doble propiedad trascendental del ente de ser verdadero y bueno, ${ }^{53}$ definirán los dos grandes grupos o géneros de facultades que Santo Tomás descubre como principio de nuestra vida intencional. Y en este sentido la Persona, por su actividad intencional, está ordenada a Dios: El que Es, y como tal, el único objeto saciativo de su inteligencia y de su amor.

Tanto el conocimiento como el amor entrañan cierta trascendencia, cierta superación de la individualidad. Pero mientras el conocimiento supone una posesión puramente representativa o intencional (ya que por el conocimiento el sujeto se une con lo conocido, pero no en el mismo ser real que lo conocido tiene en sí, sino en el ser representativo que tiene en el cognoscente); por el amor, en cambio, el sujeto tiende a la posesión real de lo amado, a unirse con éste según su ser real y no sólo en la representación.

De esta manera, el amor completa la trayectoria del perfeccionamiento del hombre: Por el conocimiento, el hombre había ascendido del conocimiento de las cosas y de los demás hombres hasta el conocimiento de Dios. El amor, por su parte, une al hombre con la Naturaleza, con su prójimo, con Dios, en una unión que, de momento, es tan sólo intencional, afectiva; pero que está ordenada de sí, como a su fin, a una unión real, secundum esse naturale.

Por consiguiente, el prototipo de la acción y de la vida perfecta hay que buscarlo en la actividad y en la vida intimas que por el conocimiento y el amor unen a los seres personales entre sí y con Dios: Se trata, pues, de la teoría de la primacía de la contemplación, que es considerada la forma de actividad u operación más perfecta. ${ }^{54}$

Ya para acabar, y a modo de conclusión, debemos destacar que la doctrina de la escala de los seres de Santo Tomás, en la que se integran sus tesis acerca de la perfección y orden del Universo, constituye un fiel reflejo de su filosofía del ser. Así, los grados de perfección que

52 Idem, Summa Theologiae, I, q. 65, a. 2.

53 Conocimiento y amor son la expresión y repercusión en el alma de dos propiedades trascendentales del ente: la verdad y la bondad (que son perfectivas del alma).

54 Por tanto, si realmente la culminación de toda perfección finita estriba en la contemplación, ésta debe ser entendida no sólo como un acto de conocimiento sino, además, como un acto de amor. Y esta solución que permite superar en amplitud y en profundidad todo intelectualismo y también todo voluntarismo es la adoptada por el propio Santo Tomás y que se desprende de la correcta interpretación de sus textos. Cf. Bofill, J., La escala de los seres, op. cit., pp. 163 ss. 
aparecen en la escala de los seres no son concreciones o determinaciones contenidas en alguna categoría de los entes, sino que constituyen distintas participaciones del ser: El ser es la perfección máxima, por lo que no es perfectible o receptivo de perfecciones, sino que es siempre perfectivo. Lo que ocurre es que en los entes el ser es participado y limitado al ser recibido en una esencia finita, por lo que se posee la perfección según el grado de limitación o reducción que marca la esencia. En definitiva, los grados de perfección no pueden ser adecuadamente entendidos si no es como grados en la mayor y más perfecta posesión del ser, ya que toda perfección y nobleza de cualquier ente le pertenece según su ser. 